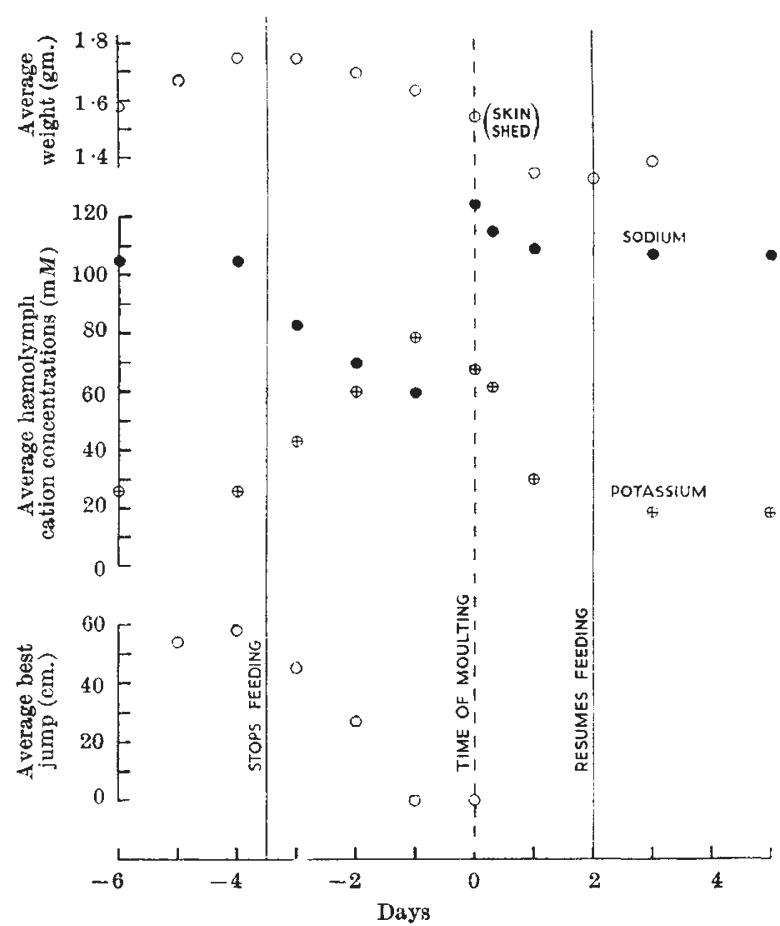

Fig. 1. Physiological changes occurring in flfth-instar nymphs of Iocusta at the time of moulting. Top, changes in weight : centre, changes in hæmolymph sodium and changes in weight; centre bottom, changes in muscular power indicated by length of jump

each individual graphically. The weight of a hopper rises steadily, increasing by about $0 \cdot 1 \mathrm{gm}$./day until eventually the animal ceases feeding. Thereafter the hoppers lose weight at the rate of about $0.6 \mathrm{gm}$. $/$ day, until after about thrae and a half days following the cessation of feeding the moult occurs. By following the changes in weight it is possible to ascertain approximately the time at which a hopper will moult.

It was found to be possible to follow the progress of a batch containing as many as 40 hoppers. A fow individuals were removed from the batch at times estimated to be $4,3,2$, and 1 days before their moult, during the moult and $6 \mathrm{hr}, 1,3$ and 5 days following the moult. 2 c.mm. of hæmolymph was withdrawn from each hopper after making a small puncture behind the pronotum. The sodium and potassium contents were determined with the aid of a flame photometer. Blood was withdrawn from each hopper once only before the moult. Before being returned to the cage each animal was made to jump and the longest jumps were measured.

In Fig. 1 the results of the analyses of the hæmolymph of a group of gregarious-type fifth-instar hoppers of Locusta migratoria migratorioides R. and F. are plotted against time in relation to moulting. The average weights, average best jumps, times of cessa. tion and resumption of feeding and the time of moult. ing are all indicated on the same time-scale. The time of moulting, which was known accurately in many cases or to within not more than $12 \mathrm{hr}$, was taken as a fixed point. Other points are subject to an error of the order of $\pm 8 \mathrm{hr}$. in relation to the indicated time of onset of moulting.

The results show that starting at about the time when feeding stops, the potassium concentration in the hæmolymph rises steadily to a peak value of about $80 \mathrm{~m} . \mathrm{mol} . / \mathrm{l}$. while at the same time the sodium concentration falls to about $60 \mathrm{~m} . \mathrm{mol}$./l. During this time the sum of sodium plus potassium concentrations remains constant at about $140 \mathrm{~m} \cdot \mathrm{mol} . / \mathrm{l}$. At the moment of moulting both the sodium and the potassium values are extremely variable, but it is evident that there is a fairly abrupt increase in the sodium level, values greater than $200 \mathrm{~m} . \mathrm{mol}$./l. having been obtained. There is a corresponding, although smaller, fall in potassium level at about the same time. Thereafter sodium and potassium soon attain the normal adult concentration.

The rise in potassium concentration is adequate to account for the depolarization and partial neuromuscular block which occurs and is probably responsible for much of the inactivity and weakness of the pre-moult hoppers. Potassium ions may therefore play an important part in the achievement of the behaviour changes associated with moulting. Preliminary investigations, now in progress, show that a rise in hæmolymph potassium concentration occurs before moulting in other insect orders.

Department of Zoology,

G. HoYLe

University of Glasgow. Sept. 19.

1 Hoyle, G., J. Physiol., 1\&2, 90 (1955).

\section{Change in the Metabolism of Micro- organisms grown on Irradiated Culture Medium}

O. Wyss et al. ${ }^{1}$ report that the growth of drugresistant pathogen micro-organisms grown on culture media irradiated with ultra-violet rays increased strikingly without the micro-organisms themselves being exposed to the action of irradiation. The experiments demonstrated that mainly in cultures containing protein, under the action of ultraviolet rays the oxidation-reduction potential showed an average decrease of $300 \mathrm{mV}$., whereas under that of X-rays the decrease was 100 $110 \mathrm{mV}$.; at the same time the value of the redox capacity increased too. In order also to find an energetic explanation for the change of the metabolism of the micro-organisms cultured on irradiated medium the following tests were carried out on aerobic cultures of Serracia marcesens strains. The strains examined were inoculated into the medium irradiated with ultra-violet rays of a quartz mercury lamp for $3 \mathrm{hr}$., and simultaneously the increase of the cell count, the oxidation-reduction potential and prodigiosin production were measured.

It was established that the growth of the cultures only started when the strain had completely exhausted the redox capacity, which had increased on the action of the irradiation of the medium with ultra-violet rays. Afterwards the growth of the cells and the oxidation-reduction potential of the cultures corresponded approximately to that of the controls; the prodigiosin production, however, decreased significantly.

A. FrAmr.

E. Pettkó

M. Sipos

Chemical and Biochemical Institute, Medical University,

Szeged.

Aug. 29.

${ }^{1}$ Wyss, O., Haas, F., Clark, J. B. and Stone, W. S., J. Cell Comp. Physiol., 35, Supp. 2, 133 (1950). 